Criar Educação, Criciúma, v. 10, nº1, jan/jul 2021.- PPGE - UNESC - ISSN 2317-2452

\title{
LIBRAS: CONTEXTO HISTÓRICO DE POLÍTICAS AFIRMATIVAS PARA A INCLUSÃO
}

\author{
Angela Araújo Costa, ${ }^{1}$ \\ Wânia Maria de Araújo, ${ }^{2}$
}

\section{RESUMO}

Este artigo tem como objetivo apresentar o processo de desenvolvimento da Língua Brasileira de Sinais - Libras na educação, bem como compreender as orientações legais no que tange a inserção do ensino obrigatório da Libras no ensino superior. A abordagem metodológica do presente artigo é qualitativa e o texto aqui apresentado é fruto de uma pesquisa bibliográfica realizada a partir de palavras-chaves como Educação Inclusiva, Libras e Cultura Surda. Também foi realizada uma pesquisa documental em torno da legislação vigente sobre o ensino obrigatório da Libras que tomou como referência a Constituição Federal promulgada em 1988, a Lei no 10.436/2002, o Decreto ํo 5.626/2005 e a Lei oํ 13146/2015 que dispõem sobre deficiência, inclusão social e difusão da Língua Brasileira de Sinais - Libras. Busca-se como resultado da reflexão aqui apresentada explicitar o aporte técnico, teórico e prático para a disciplina de Libras nos cursos superiores baseados na legislação vigente.

Palavras-chave: Libras. Inclusão Social. Educação Inclusiva.

\section{LIBRAS: HISTORICAL CONTEXT OF AFFIRMATIVE POLICIES FORINCLUSION}

\section{ABSTRACT}

This article aims to present the development process of the Brazilian Sign Language - Libras in education, as well as to expose the legal guidelines regarding the insertion of the compulsory education of Libras in the higher education. This article follows a qualitative approach method and its text is the result of a bibliographical research conducted using keywords such as Inclusive Education, Libras and Deaf Culture. A documental research around the current legislation on the compulsory Libras education that took as reference the Federal Constitution promulgated in 1998, law number 10.436/2002, decree number 5.626/2005 and law number $13146 / 2015$ which deals with disability, social inclusion and language diffusion of the Brazilian Sign Language - Libras was also carried out. The intended results of this reflexion is to present the technical, theoretical and practical contribution to the discipline of Libras in higher education courses based on current legislation.

Keywords: Libras. Social Inclusion. Inclusive Education.

\footnotetext{
${ }^{1}$ Mestranda do Programa de Pós-Graduação em Gestão Social, Educação e Desenvolvimento Local do Centro Universitário Una. Professora Universitária. Especialista em Libras. Advogada. Licenciada em Letras. E-mail: angelacosta.adv@gmail.com.

2 Professora do Programa de Pós-Graduação em Gestão Social, Educação e Desenvolvimento Local no Centro Universitário Una. Tem mestrado e doutorado em Ciências Sociais pela Pontifícia Universidade Católica de Minas Gerais (PUCMINAS). E-mail: wania.maria@yahoo.com.br.
} 


\section{INTRODUÇÃO}

No momento presente, observa-se uma preocupação com a difusão da Libras, principalmente nos veículos de comunicação que tentam demonstrar a utilização das Libras como uma forma de inclusão social presente nos meios de comunicação. Entretanto, esta é uma ação ainda tímida, tendo em vista o pouco conhecimento da sociedade em relação a essa língua.

Embora as leis tenham avançado nos programas de políticas públicas voltadas à educação inclusiva, a Libras é ainda desconhecida pela maioria dos alunos do ensino superior. Diante desse contexto, se faz necessário investigar esta segunda língua brasileira reconhecida, de ensino obrigatório na educação superior com o intuito de ser difundida na sociedade. Para tanto, é importante analisar o processo de surgimento e desenvolvimento dessa modalidade linguística e compreender as orientações legais no que tange a sua inserção como conteúdo obrigatório no ensino superior.

Analisar e compreender o processo de inclusão social e suas implicações no desenvolvimento local tem relevância, principalmente, se uma das finalidades for o fomento da ciência com vistas a contribuir por meio da pesquisa para 0 desenvolvimento da educação especial. Com efeito, é importante destacar a imprescindibilidade da Libras na formação de novos profissionais e a sua aplicabilidade no dia a dia, afinal, os surdos possuem um cotidiano marcado pelas mesmas necessidades diárias dos ouvintes.

Assim, a inserção da Libras como disciplina curricular obrigatória é importante para a inclusão social, pois educar é incluir. Sem dúvida, a aprovação e promulgação da Lei $n^{0} 10.436 / 2002^{3}$ foi uma grande conquista, afinal, foi a partir dessa legislação que houve o reconhecimento a Língua Brasileira de Sinais como língua oficial.

\footnotetext{
${ }^{3}$ A referida Lei dispõe sobre a Língua Brasileira de Sinais - Libras, promulgada em 24 de abril de 2002 , em que o Congresso Nacional a Decreta e a sanciona trazendo como assunto principal o Reconhecimento da comunicação e expressão da Libras como meio de comunicação legal no Brasil, ou seja, reconhecida como segunda língua oficial. Ainda determina que o Poder Público, bem como as empresas e concessionárias de serviço público tem a obrigação de difundir a Libras, e ainda, a
} 
Criar Educação, Criciúma, v. 10, nº1, jan/jul 2021.- PPGE - UNESC - ISSN 2317-2452

A preocupação de inserir a Língua de Sinais na formação profissional superior, bem como disseminar a cultura surda, é uma forma de integrar as culturas entre surdos e ouvintes, em busca da verdadeira inclusão social. Em dezembro de 2005, a Lei no $10.436 / 2002$, foi regulamentada pelo Decreto Lei o 5.626 que inseriu a Libras como disciplina curricular obrigatória nos cursos de formação de professores para o exercício do magistério, nível médio e superior, nos cursos de fonoaudiologia e como disciplina optativa nos demais cursos superiores.

Frente a estas questões, o presente artigo tem como objetivo investigar o surgimento e desenvolvimento da Libras por meio de pesquisa bibliográfica, para a construção de uma análise sistematizada do processo constitutivo dessa modalidade linguística e para compreender as orientações legais no que tange a sua inserção no ensino superior.

\section{EDUCAÇÃO DOS SURDOS}

Conforme assinala Goldfeld (1997) as crianças nascidas com algum tipo de deficiência eram deixadas nas estradas para morrerem à míngua ou serem sacrificadas, e quando deixadas vivas eram rejeitadas pela sociedade. No âmbito das deficiências, o surdo era tratado como uma pessoa castigada pelos Deuses e/ou como pessoa enfeitiçada. Sendo assim, eram excluídas da sociedade ou também sacrificadas. Os surdos não podiam ser educados, pois viviam totalmente à margem da sociedade e não detinham nenhum direito assegurado. Essa ideia foi modificada somente a partir do século XVI quando surgiram pessoas interessadas na educação dos surdos, mas a ideia de educá-los partiu do interesse de investir no seu potencial para o trabalho.

Em torno de 1712 surgiu na França a primeira escola para crianças surdas com o Abade Michel de L'Epeé (1712 -1789), onde foi utilizada pela primeira vez a língua de sinais com o objetivo de ensinar a ler, escrever e dar acesso à educação. O método

obrigatoriedade nos cursos de formação de Educação Especial, Fonoaudiologia e Magistério, em níveis médios e superiores, como parte integrante dos PCN's - Parâmetros Curriculares Nacionais, e, por fim, garantir assistência e tratamento adequado no âmbito da saúde aos portadores de deficiência auditiva. 
Criar Educação, Criciúma, v. 10, n¹, jan/jul 2021.- PPGE - UNESC - ISSN 2317-2452

trazido por L'Epeé teve muito sucesso e acabou por influenciar a língua de sinais nos Estados Unidos (1864) e na Alemanha (1950) (SACKS, 1989).

No Brasil o primeiro Instituto dos Surdos-Mudos foi fundado em 1857 no Rio de Janeiro por Ernest Huet, hoje denominado como Instituto Nacional de Educação dos Surdos - INES. O INES é um órgão do Ministério da Educação e até hoje é o centro de referência na área da surdez no Brasil (GOLDFELD,1997).

No início, os alunos do INES eram educados por linguagem escrita e falada e datilologia de sinais, bem como a "leitura sobre os lábios". Os sinais foram trazidos da França por Huet, e com isso, a Língua de Sinais Brasileira possui forte influência da Língua de Sinais Francesa. Mas vale a pena frisar que os trabalhos de oralização realizados no INES eram feitos por professores "comuns", pois, não haviam especialistas na comunicação de sinais. Diante da necessidade de comunicação, os surdos começaram a habitar os corredores do instituto utilizando a língua de sinais, assim a comunidade surda veio conquistando seu espaço na sociedade (GOLDFELD,1997).

Os recentes estudos a respeito da educação brasileira do século XIX, particularmente no período imperial, têm demonstrado que havia, em várias Províncias, uma imensa discussão acerca da necessidade de escolarização da população, sobretudo das camadas "inferiores da sociedade". Questões como a necessidade e a pertinência ou não da instrução dos negros (livres, libertos ou escravos), índios e mulheres eram amplamente debatidas e intensa foi a atividade legislativa das Assembleias Provinciais em busca do ordenamento legal de educação escolar (FARIA FILHO, 2010, p.132).

As crianças surdas tinham a obrigação de aprender lições de pronúncia e de articulação e priorizavam o trabalho para o ensino da língua oral ou oralização, sendo que a sistematização escrita somente foi iniciada em 1874, por Tobias Leite, diretor do Instituto.

De acordo com Goldfeld (1997) o Oralismo ou filosofia oralista visa a integração da criança com surdez na comunidade de ouvintes, dando-lhe condições de desenvolver a língua oral (no caso do Brasil, o português). Para alguns defensores desta filosofia, a linguagem restringe-se à língua oral sendo por isso mesmo esta, a única forma de comunicação dos surdos. Acreditam assim que para a criança surda se comunicar é necessário que ela saiba oralizar (POKER, 2002, p 5). 
Em torno de 1950 foi criado o primeiro Curso Normal para professores de surdos, impulsionado por Ana Rímoli de Faria Dória, nova diretora do Instituto SurdoMudo. O curso teve como justificativa a quantidade de surdos espalhados pelo Brasil e a impossibilidade no INES atender a todos os alunos surdos espalhados pelo país (RODRIGUES; GONTIJO, 2017).

Ainda segundo Rodrigues e Gontijo (2017), na década de 1950 não havia legislação no Brasil que tratava especificamente dos surdos ou sobre a educação dos surdos $\mathrm{O}$ seu acesso à educação aconteceu por meio do INES e Secretarias da Educação.

Após o método de oralização que priorizava o treino da fala e a leitura labial, o segundo método adotado para a educação dos surdos foi mesclando a oralização com a língua de sinais, denominado Comunicação Total. Um método que pouco contribui, pois levou a inequação o "português sinalizado", defendendo a educação através de qualquer recurso linguístico, seja pela língua de sinais, linguagem oral ou códigos manuais (POKER, 2002).

Ainda segundo Poker (2002) a terceira e última modalidade que ganhou força foi a filosofia do Bilinguismo. Essa modalidade parte do princípio de que o surdo deve aprender primeiramente a Língua de Sinais com a comunidade surda, e a língua portuguesa seria ensinada como segunda língua na modalidade escrita. Isso porque a Língua de Sinais foi vislumbrada como importante para o desenvolvimento e conhecimento do surdo valorizando sua forma de cultura e língua própria.

A proposta do Bilinguismo ainda é utilizada no Brasil e foi reforçada pelas legislações brasileiras que instituíram a Língua de Sinais como língua materna para os surdos.

\subsection{LIBRAS: ANTES DE UMA DISCIPLINA, UMA LÍNGUA}

Antes de pensar estritamente na obrigatoriedade de uma disciplina, é necessário refletir que a Libras é uma modalidade linguística que precisa ser compreendida como uma língua presente na sociedade brasileira. Desta forma, para 
Criar Educação, Criciúma, v. 10, n¹, jan/jul 2021.- PPGE - UNESC - ISSN 2317-2452

se estudar a língua deve-se conhecer suas características, concepções, e especificidades, pois é por meio da linguagem que se constrói conhecimentos e nos tornamos sujeitos pensantes (SANTOS, 2015).

A Língua de Sinais é a linguagem do silêncio e isso faz surgir a necessidade do contato visual, para a expressão das emoções, por isso distância e postura, são elementos essenciais para a comunicação. Assim, segundo Knapp; Hall (19994 apud FELIPE, 2013, p. 74), "essa abordagem transdisciplinar para o estudo da psicologia do corpo social poderá desvendar essa linguagem de silêncio que se coarticula, enquanto comunicação verbo-visual, com a comunicação verbo-oral".

De acordo com Felipe (2013) essa interação social está relacionada às expressões faciais e corporais denominadas "linguagem do silêncio", e na perspectiva da análise face-corporal o autor caracterizou dois tipos de expressões visuais: a expressão visual afetiva e os signos gramático-discursivos visuais.

As expressões visuais afetivas são denominadas comunicações paralinguísticas complementares que na verdade são aquelas expressões capazes de demonstrar os sentimentos do locutor e interlocutor por meio de gestos, postura corporal, expressões corporais, faciais e do olhar. São os estados e sensações demonstrados por meio das expressões, como os estados de alegria, tristeza, angústia, dúvida, entre outras emoções (FELIPE, 2013).

Já os signos gramáticos - discursivos visuais "são marcas verbo-visuais" e "fazem parte da arquitetura dos níveis fonológico, morfológico, sintático-semântico e discursivo", concluindo assim uma comunicação social (FELIPE, 2013).

A Libras deve ser a primeira língua de contato do surdo e os movimentos das mãos correspondem a significação de uma ideia por meio das palavras e frases. Os movimentos são de extrema importância, pois correspondem a língua falada. Vale ressaltar que essa correspondência se diferencia da língua portuguesa em alguns aspectos, pois os artigos não são usados ao longo das frases, bem como os verbos são sempre no infinitivo (ROSSI, 2010).

\footnotetext{
${ }^{4}$ KNAPP, M. L.; HALL, J. A. Comunicação não-verbal na interação humana. Trad. Mary A. D. de Barros. São Paulo: JSN Editora, 1999.
} 
Criar Educação, Criciúma, v. 10, n¹, jan/jul 2021.- PPGE - UNESC - ISSN 2317-2452

Diante da complexidade da Libras é necessário refletir sobre a sua aplicabilidade como disciplina, já que não é explicitado na legislação as normas relativas à duração, ao conteúdo ou plano de ensino a ser ministrado nas instituições de ensino regular. Com efeito, é importante saber suas regras e estrutura ao analisar as matrizes curriculares para compreender como é e como pode ser o ensino obrigatório da Libras nos cursos de Pedagogia e Fonoaudiologia em instituições de Belo Horizonte considerando a Política Nacional de Educação Especial na Perspectiva da Educação Inclusiva.

Há de se refletir que a Libras é uma modalidade linguística e possui especificidades adquiridas ao longo do tempo como qualquer outra língua. A informação disponível no Portal da Educação do Ministério da Educação (MEC) é somente relativa à carga horária de um curso básico de Libras: 160 horas. A referência de carga horária mínima ditada pelo MEC demonstra que para se ter o conhecimento básico de uma língua é imprescindível tempo (hora/aula) para que de fato haja compreensão e habilidades linguísticas (BRASIL, 2018).

\subsection{LÍNGUA BRASILEIRA DE SINAIS NO CONTEXTO DO ENSINO BRASILEIRO}

Em 1500 quando os portugueses chegaram ao Brasil, a educação escolar dos surdos na Europa já dava seus primeiros passos. No Brasil o início da educação escolar dos surdos somente começou a partir de 1857. O imperador Dom Pedro II se interessou pela educação dos surdos no século XIX, pois o príncipe Luís Gastão de Orléans, marido de sua segunda filha, a princesa Isabel, era deficiente auditivo, sendo parcialmente surdo. Entretanto, não se tem a confirmação desse fato. Mesmo sem essa certeza histórica, pode-se dizer que o interesse de Dom Pedro II foi essencial para a educação dos surdos, pois ele convidou Ernest Huet, professor francês e sua esposa, em 1855, para fundar o Instituto dos Surdos-Mudos, ainda hoje, uma referência na educação dos surdos no Brasil.

Segundo Strobel (2008), o pedagogo pioneiro da educação surda no Brasil, Ernest Huet, se afastou de suas atividades depois de cinco anos à frente do INES. A escola utilizou a língua de sinais francesa trazida por Huet misturando com a existente 
Criar Educação, Criciúma, v. 10, nº1, jan/jul 2021.- PPGE - UNESC - ISSN 2317-2452

no Brasil, o que deu origem a Língua Brasileira de Sinais - Libras. Dessa forma, como outras línguas, a Libras se constitui a partir da influência de outras línguas de sinais.

A partir de 1980 e 1990, surge no Brasil a educação chamada de Comunicação Total, uma filosofia com o objetivo de contemplar toda forma de comunicação, seja pela fala, sinais, dança, teatro, mímica etc. Assim, as escolas especiais que estavam enraizadas no oralismo perderam força, pois os professores começaram a aprender sinais com os alunos surdos, "Um clamor se levantou na educação especial para a abertura de novos caminhos, caminhos estes mais democráticos, mais naturais com o uso dos sinais" (MORI; SANDER, 2015, p. 10).

Como já explicitado, historicamente os surdos foram estigmatizados e até considerados "humanamente inferiores", e por serem discriminados e segregados, surdos se organizaram em grupo pela identificação que tinham e estabeleceram uma cultura "entre surdos e ouvintes há uma grande diferença que os distingue: a linguagem oral" (SANTANA; BERGAMO, 2005, p. 566).

Cultura surda é a forma que o sujeito surdo entende o mundo e a forma que o modifica a fim de torná-lo acessível, ajustando-o com as suas percepções visuais que contribuem para o conceito das identidades surdas e de suas comunidades. Significa que a cultura abrange a língua, a ideia, a crença, o costume e todo o hábito da comunidade surda (SILVA, 2002).

As identidades surdas são construídas dentro das representações possíveis da cultura surda, elas moldam-se de acordo com o menor ou maior receptividade cultural assumida pelo sujeito. E dentro dessa receptividade cultural, também surge aquela luta política ou consciência oposicional pela qual o indivíduo representa a si mesmo, se defende da homogeneização, dos aspectos que tornam corpo menos habitável, da sensação de invalidez, de inclusão entre os deficientes, de menos valia social (PERLIN, 2006, p. 77-78).

Segundo Santana e Bergamo (2005), o surdo adquire a identidade surda quando domina a língua de sinais, já que não é ouvinte. Nesse sentido, a ideia de identidade surda está relacionada ao uso da língua de sinais, sua aquisição é a única capaz de oferecer uma identidade ao surdo. Porém, existem surdos que se identificam de forma diferente, ou seja, a discussão é muito complexa.

A identidade dever ser vista como práticas discursivas e sociais que enunciam o entrecruzamento de papéis sociais que os indivíduos desempenham. Assim, as 
normas de identidade do surdo correspondem também a uma norma cultural surda partindo do pressuposto de que a identidade é uma prática que é entrelaçada por várias condutas e comportamentos sociais compartilhando entre si suas dificuldades, ambições, sucessos e sonhos (SANTANA; BERGAMO, 2005).

A cultura surda exprime valores e crenças que se originaram e foram transmitidos pelos sujeitos surdos ao longo de gerações. Várias são as questões pertinentes à cultura surda no Brasil, primeiramente em relação aos aspectos de reconhecimento da identidade vivenciada pelos sujeitos surdos, seus valores sociais e linguísticos, ou seja, de todo um processo histórico-cultural (ALMEIDA, 2015).

A educação dos surdos deveria ser contemplada pelas políticas públicas com vistas a garantir o acesso e a permanência do aluno surdo nas escolas regulares de ensino. Assim, segundo Quadros (2012), a legislação vigente garante o direito linguístico ao surdo, e ao mesmo tempo o acesso "dentro da rede regular na escola da esquina de seu bairro". Entretanto, tal acesso é barrado pela falta de estrutura, material didático apropriado e profissionais qualificados. Como o ensino da Libras não é obrigatório nas escolas regulares não há interesse de ter aulas de uma língua em que a maioria dos alunos desconhecem ou porque nunca tiveram contato ou nunca tentaram se aproximar de um surdo (ALMEIDA, 2015).

Ainda segundo Quadros (2012), os próprios articuladores que planejam as estratégias de políticas públicas de educação chegam à conclusão de que isso seria "extremamente dispendioso e acabaria criando situações garantidas por lei, mas sem serem concretizadas" (QUADROS, 2012, p. 143), ou seja, um amparo legal sem recursos para ser efetivado na prática.

Diante de tais dificuldades, o poder público cria, então, estratégias para que a língua dos surdos seja disponibilizada na rede de ensino regular. Uma das estratégias foi a obrigatoriedade de intérprete para cada aluno surdo matriculado na rede regular de ensino, e que esse intérprete seja custeado pela instituição, conforme disposto no Decreto $\mathrm{n}$-5.626, de 22 de dezembro de 2005, que na verdade regulamenta uma lei que já existia, a Lei oํ 10.436, de 24 de abril de 2002.

Ao analisar a legislação vislumbra-se um avanço político que reconhece a necessidade do bilinguismo. Entretanto, tal política de inclusão se efetivaria se o 
Criar Educação, Criciúma, v. 10, nº1, jan/jul 2021.- PPGE - UNESC - ISSN 2317-2452

tratamento daqueles que possuem uma língua minoritária se consolidasse na sociedade, "a educação bilíngue para surdos constitui um território de disputas em que Libras e língua portuguesa estão em tensão constante nas interações verbais" (FERNANDES, 2011, p. 60).

Nesse cenário, a inclusão de crianças e jovens surdos no contexto escolar deveria ser percebido como uma educação transformadora, em que experiências linguísticas e culturais diferentes fossem mediadas e organizadas em espaços comuns de escolarização. As escolas bilíngues são necessárias para uma educação revolucionária e verdadeiramente inclusiva, bem como efetivaria o tratamento jurídico expresso pelo Estado (FERNANDES; MOREIRA, 2014).

\section{SURDOS EM ESCOLAS COMUNS}

O Decreto $n^{\circ}$ 5.626/2005, instituiu em seu título "DO USO E DA DIFUSÃO DA LIBRAS E DA LÍNGUA PORTUGUESA PARA O ACESSO DAS PESSOAS SURDAS À EDUCAÇÃO", que as instituições devem garantir, obrigatoriamente, o atendimento especializado e acesso à educação, desde a educação infantil quanto ao ensino superior.

Art. 14. As instituições federais de ensino devem garantir, obrigatoriamente, às pessoas surdas acesso à comunicação, à informação e à educação nos processos seletivos, nas atividades e nos conteúdos curriculares desenvolvidos em todos os níveis, etapas e modalidades de educação, desde a educação infantil até à superior.

$\S 1$ 10 Para garantir o atendimento educacional especializado e 0 acesso previsto no caput, as instituições federais de ensino devem:

d) professor regente de classe com conhecimento acerca da singularidade linguística manifestada pelos alunos surdos;

IV - garantir o atendimento às necessidades educacionais especiais de alunos surdos, desde a educação infantil, nas salas de aula e, também, em salas de recursos, em turno contrário ao da escolarização (BRASIL, 2005).

De acordo com Quadros (2012), mesmo diante das leis existentes a política educacional mantém uma distância entre o "prescrito e o executado", pois, em alguns estados brasileiros, os próprios surdos e seus familiares têm que acionar o judiciário 
Criar Educação, Criciúma, v. 10, n¹, jan/jul 2021.- PPGE - UNESC - ISSN 2317-2452

para exigir o ensino na língua brasileira de sinais nas escolas, mais uma vez ratificando as dificuldades supramencionadas.

Como forma de interagir com o entendimento sobre a necessidade dos surdos terem que acionar o judiciário em busca de seus direitos, Quadros (2012), demonstra por meio de jurisprudência, ou seja, conjuntos de decisões, aplicações e interpretações das leis, que mesmo após cominações por meio das Legislações Brasileiras, muitas instituições de ensino somente cumprem o determinado mediante ações judiciais.

O entendimento do Tribunal de Justiça de Minas Gerais - TJMG instrui por meio de jurisprudências que é dever do Estado garantir o atendimento educacional especializado aos deficientes preferencialmente na rede regular de ensino, conforme estabelecido pela Constituição em seu artigo 208, inciso III.

No caso dos surdos, não havendo professores devidamente habilitados e com domínio da Língua Brasileira de Sinais, aptos a ministrarem aulas para o aluno surdo, nem tendo o Estado apresentado qualquer outra solução possível, como a matrícula em outra escola comum com serviço de apoio especializado ou a possibilidade de atendimento em classe, escola ou serviço especializado (art. $58, \S \S 1^{\circ}$ e $2^{\circ}$ da Lei $n^{\circ}$ 9.394 /96), o educando tem o direito subjetivo, garantido constitucionalmente, de ser acompanhado por um intérprete, até a conclusão do ensino médio.

Frente às dificuldades apontadas de um intérprete ou professor habilitado em Libras nas escolas regulares, surgem mecanismos para suprir alguns problemas, como por exemplo, o curso de Letras Libras Bacharelado em nível de pós graduação que formará profissionais para responder a esta demanda perante as instituições de ensino, bem como iniciativas para a formação de intérpretes de Língua de Sinais.

A educação no país ainda reflete os princípios da política de integração traduzidos como a colocação de surdos na rede regular que ensina a língua portuguesa. Esse é o grande entrave do processo inclusivo dos surdos na educação, impondo um desafio para as propostas governamentais, no sentido de garantir os direitos deles. A implementação de uma política de inclusão deve estar acompanhada do diálogo com os movimentos representantes dos surdos que, apesar de insatisfeitos, estão interessados no sucesso de sua educação (QUADROS, 2012, p. 77). 
Criar Educação, Criciúma, v. 10, n¹, jan/jul 2021.- PPGE - UNESC - ISSN 2317-2452

As políticas públicas educacionais ainda necessitam ser consolidadas para garantirem a inserção da Língua Brasileira de Sinais no ensino regular, bem como uma educação de surdos no contexto e cultura dos ouvintes. As proposições ultrapassam as questões linguísticas, incluindo aspectos culturais, sociais e políticos como será analisado adiante.

\title{
3.1 A EDUCAÇÃO INCLUSIVA
}

O tema relativo à história das pessoas com deficiência ${ }^{5}$ passou a ter presença no século XIX, quando estudiosos brasileiros influenciados por meio de experiências positivas realizadas na França e nos Estados Unidos, organizaram e implementaram ações para atender as pessoas com necessidades especiais, sejam aquelas com necessidades físicas, mentais e sensoriais (DOMINGOS, 2005).

As iniciativas precisaram de mais de um século para se concretizarem de maneira mais evidente, pois não estavam integradas às políticas públicas de educação (MAZZOTA, 1996).

\begin{abstract}
$\mathrm{Na}$ estruturação da educação brasileira, o discurso científico, as ideias de modernização e racionalização estão presentes desde os primórdios da educação especial também. A crença nas "potencialidades inatas" vai fundamentar um pensamento meritocrático, presente em nossa história passada e também na organização da sociedade atual. A evolução dos serviços de educação especial caminhou de uma fase inicial, eminentemente assistencial, visando apenas o bem-estar da pessoa com deficiência, para uma segunda, em que foram priorizados os aspectos médicos e psicológicos, chegando às instituições de educação escolar e provocando a integração da educação especial no sistema geral de ensino (DOMINGOS, 2005, p. 20).
\end{abstract}

Mesmo que desde 1988 tenha sido iniciado a discussão sobre educação inclusiva, foi em 1994, com a Declaração de Salamanca que houve uma ampliação

\footnotetext{
${ }^{5}$ A deficiência é complexa, dinâmica, multidimensional, e questionada. Nas últimas décadas, o movimento das pessoas com deficiência, juntamente com inúmeros pesquisadores das ciências sociais e da saúde têm identificado o papel das barreiras físicas e sociais para a deficiência. A transição de uma perspectiva individual e médica para uma perspectiva estrutural e social foi descrita como a mudança de um "modelo médico" para um "modelo social" no qual as pessoas são vistas como deficientes pela sociedade e não devido a seus corpos (Relatório Mundial sobre a Deficiência, Publicado pela Organização Mundial da Saúde em 2011).
} 
Criar Educação, Criciúma, v. 10, n¹, jan/jul 2021.- PPGE - UNESC - ISSN 2317-2452

da discussão com o reconhecimento de que "[...] as pessoas com necessidades especiais devem ter acesso às escolas comuns que deverão integrá-las numa pedagogia centralizada na criança, capazes de atender a essas necessidades" (UNESCO, 1994, p. 10). Assim, a educação inclusiva ganhou vez e voz. Com efeito, o tema educação para todos passou a ser a proposta do Estado Brasileiro.

As discussões ainda merecem atenção mesmo após a declaração de Salamanca (1994) e a Constituição Federal de 1988 que garantem o direito público à educação de todos, inclusive das pessoas com deficiência, preferencialmente, junto à rede regular de ensino.

Após a Constituição de 1988 foi promulgada a Lei nำ 7.853, de 24 de outubro 1989 que ampliou a educação inclusiva, dispondo sobre a integração social, instituindo a tutela jurisdicional e interesses coletivos das pessoas com deficiência, bem como disciplina a atuação do Ministério Público que define inclusive crimes acerca do tema.

Após dez anos, foi regulamentado o Decreto Lei no 3.298 de 1999, com o caráter de ampliar ainda mais as normas de proteção às pessoas com deficiência, consolidando normas de proteção.

Mediante programas de apoio para o aluno que está integrado no sistema regular de ensino, ou em escolas especializadas exclusivamente quando a educação das escolas comuns não puder satisfazer as necessidades educativas ou sociais do aluno ou quando necessário ao bem-estar do educando (BRASIL, 1999).

Diante destas reformas quanto à educação inclusiva, há de se destacar a Lei de Diretrizes e Base para a Educação Nacional (LDB), de 1996, com a descrição do tema "Educação Especial", introduzida com o texto:

Art. 58. Entende-se por educação especial, para os efeitos desta Lei, a modalidade de educação escolar, oferecida preferencialmente na rede regular de ensino, para educandos portadores de necessidades especiais (BRASIL, 1996). 
Criar Educação, Criciúma, v. 10, n¹, jan/jul 2021.- PPGE - UNESC - ISSN 2317-2452

Ainda sobre o artigo 58 da LDB/96, destaca-se que sofreu alteração recentemente pela Redação dada pela Lei № 12.796, de 2013:

Art. 58. Entende-se por educação especial, para os efeitos desta Lei, a modalidade de educação escolar oferecida preferencialmente na rede regular de ensino, para educandos com deficiência, transtornos globais do desenvolvimento e altas habilidades ou superdotação (BRASIL, 2013).

Percebe-se que o texto legal amplia a descrição dos públicos alvo da educação especial, continuando a destacar que a educação escolar deve ser preferencialmente na rede comum de ensino, ou seja, a inserção dos alunos especiais deve se dar preferencialmente mediante uma convivência igualitária entre todos.

Assim, diante as normas aqui descritas, pode-se afirmar que os alunos com necessidades especiais são cidadãos com os mesmos direitos a oportunidades educacionais no processo de desenvolvimento e conhecimento, entretanto não há uma fiscalização quanto a sua aplicabilidade.

A educação inclusiva tem como objetivo realizar mudanças nos valores da educação tradicional, o que significa que deve desenvolver novas políticas de reestruturação, ou seja, uma transformação no sistema capaz de receber alunos diversos, independentemente de sua deficiência. Essa mudança pode atender a todos os indivíduos a fim de garantir a aplicabilidade de todos os direitos descritos na legislação aqui apresentada (SILVA NETO et al., 2018).

O movimento mundial pela educação inclusiva é uma ação política, cultural, social e pedagógica, desencadeada em defesa do direito de todos os alunos de estarem juntos, aprendendo e participando, sem nenhum tipo de discriminação. A educação inclusiva constitui um paradigma educacional fundamentado na concepção de direitos humanos, que conjuga igualdade e diferença como valores indissociáveis, [...] dentro e fora da escola (BRASIL, 2007, p.1).

Importante destacar que para o processo de educação inclusiva acontecer é necessário a preparação da equipe de profissionais da comunidade escolar e o desenvolvimento de recursos pedagógicos para suprir as necessidades dos alunos especiais, afinal "não podemos falar somente em inclusão escolar de forma passional, 
Criar Educação, Criciúma, v. 10, nº1, jan/jul 2021.- PPGE - UNESC - ISSN 2317-2452

mas devemos fazer o debate segundo a visão de quem faz a escola, sejam professores, coordenadores, diretorias, porteiros, entre outros" (SILVA NETO et al., 2018, p. 84 ).

Não basta no âmbito educacional somente o cumprimento das legislações acerca da inclusão, se não houver uma equipe de fato preparada para contribuir para a real inclusão e interação dos alunos surdos na escola. É importante prezar pela permanência do aluno surdo na escola comum, a fim de garantir seu desenvolvimento, levá-lo a alcançar o seu potencial máximo, reconhecendo suas habilidades e dificuldades, pois, é missão da escola ampliar suas potencialidades e promover sua dignidade humana.

No entanto, também o deficiente, com a inclusão, encontra-se prejudicado pelo despreparo de professores, pelas formas de atendimento no sistema educacional não serem de acordo às suas necessidades. Em muitos casos são os alunos portadores de necessidades especiais que se adaptam às escolas, aos métodos dos professores, aos espaços físicos inadequados, ao invés do sistema educacional adaptar-se às suas necessidades (ROSSI, 2010, p. 74).

Ao invés de se pensar em construir novas políticas públicas seria necessário colocar em prática as já existentes, pois percebe-se que em matéria legislativa, existem diversas formas de garantia de direitos e agora é o momento de praticá-las, para que de fato ocorra a inclusão dos deficientes na escola.

A política de inclusão de alunos surdos em sistemas regulares, entretanto, é contestada pela comunidade surda, pois os surdos querem preservar a sua cultura, identidade e, com isso, defendem a ideia da escola ou classes específicas para surdos e o ensino bilíngue (RAMOS; HAYASHI, 2018).

De acordo com entendimento de Ramos e Hayashi (2018) essa perspectiva de uma escola específica para surdos "celebra a constituição de espaços acadêmicos sensiveis às suas singularidades" (RAMOS; HAYASHI, 2018, p. 250). Porém, não há um consenso quanto a educação de surdos, pois a legislação prioriza que os surdos estudem em escolas regulares, já os surdos reivindicam essa perspectiva inclusiva optando pelas escolas e classe específicas para surdos com a finalidade de priorizar a Libras, sua cultura e identidade. 


\begin{abstract}
$\mathrm{Na}$ escola especial para surdos, o discurso predominante fundamenta-se em saberes clínicos, e a surdez é concebida sob o estigma da deficiência. Nas palavras de Sá (1998, p. 189), uma escola especial que estamos acostumados a ver, ou seja, aquela"[...] que junta todos os surdos, todos os "deficientes auditivos" para "normalizá-los" [...] por sua vez, entendemos como escola regular inclusiva (tratamos aqui especificamente sobre a educação de alunos surdos) aquela em que há alunos surdos matriculados juntamente a alunos ouvintes em turmas comuns, cuja língua de instrução e interação é a língua portuguesa, falada e escrita, e, por essa razão, demanda a presença de tradutores/intérpretes de Libras/língua portuguesa - a fim de viabilizar aos alunos surdos 0 acesso aos conhecimentos e conteúdos curriculares (RAMOS; HAYASHI, 2018, p. 251).
\end{abstract}

Como já explicitado, a Legislação vigente prioriza que a educação de alunos com deficiência seja realizada pelas escolas comuns, tanto na Educação Infantil, Fundamental, Ensino Médio e Superior. Segundo Borges e Campos (2018) é inegável os avanços da educação inclusiva e a crescente entrada de alunos com deficiência nas escolas comuns, entretanto a permanência desses alunos é ainda um desafio.

\title{
4 CONSIDERAÇÕES FINAIS
}

Como a Libras é uma língua com gramática própria, necessita de tempo e prática constante para que o aprendizado se efetive. A relação ouvinte e surdo deve ser mais próxima por meio do conhecimento básico da língua de sinais, havendo maior interação entre ouvinte e surdo em que a comunicação possa fluir de modo eficaz.

A discussão aqui apresentada teve como objetivo analisar a legislação referente a inserção da Libras no ensino superior, bem como destacar que essa inserção não deveria estar descolada dos aspectos socioculturais que envolvem a cultura surda e sua existência numa sociedade predominantemente de ouvintes. Com efeito, buscou evidenciar que é necessário refletir sobre a educação inclusiva frente às necessidades dos surdos em busca da equidade perante a cultura ouvinte.

Para que as normas aplicadas alcancem esse processo equânime é também necessária a qualificação dos professores e demais profissionais do ensino superior, assim como adaptações desde o apoio pedagógico a disponibilidade de recursos e equipamentos. 
O reconhecimento da Libras como língua oficial dos surdos deve ser de fato difundido e não apenas positivado, para que os surdos sejam de fato inseridos na sociedade por meio de uma integração no ambiente escolar, favorecendo a Inclusão e valorização da Língua de Sinais.

\section{REFERÊNCIAS}

ALMEIDA, Wolney G. (org.). Educação de surdos: formação, estratégias e prática docente [online]. Ilhéus, BA: Editus, 2015, 197 p.

BRASIL. Constituição da República Federativa do Brasil: promulgada em 5 de outubro de 1988. Disponível em:

<http://www.planalto.gov.br/ccivil_03/constituicao/constituicao.htm>. Acesso: 09 de maio de 2017.

BRASIL. Lei de Diretrizes e Bases da Educação Nacional, Lei 9.394: promulgada em 20 de dezembro de 1996. Disponível em:

<http://www.planalto.gov.br/ccivil_03/leis/L9394.htm>. Acesso: 09 de maio de 2017.

BRASIL. Decreto Lei no 3298: promulgada em 20 de dezembro de 1999. Disponível em:<http://www.planalto.gov.br/ccivil_03/decreto/D3298.htm>. Acesso: 09 de julho de 2017.

BRASIL. Lei 10.436: promulgada em 24 de abril de 2002. Dispõe sobre a Língua Brasileira de Sinais - Libras. Disponível em:

<http://www.planalto.gov.br/ccivil_03/LEIS/2002/L10436.htm >. Acesso: 09 de maio de 2017.

BRASIL. Decreto no 5.626: promulgada em 22 de dezembro de 2005. Disponível em:<http://www.planalto.gov.br/ccivil_03/_ato2004-2006/2005/decreto/d5626.htm>. Acesso: 09 de julho de 2017.

BRASIL. Ministério da Educação - MEC. Atendimento Educacional Especializado: Deficiência Visual. Brasília: SE-ESP/SEED/MEC, 2007. Disponível em: <http://portal.mec.gov.br/seesp/arquivos/pdf/aee_dv.pdf>. Acesso: 09 de julho de 2017.

BRASIL. Lei 13.16: promulgada em 06 de outubro de 2015. Disponível em: <http://www.planalto.gov.br/ccivil_03/_ato2015-2018/2015/lei/L13168.htm>. Acesso: 31 de jan. 2018. 
BRASIL. Lei 13.146: promulgada em 06 de julho de 2015. Institui a Lei Brasileira de Inclusão da Pessoa com Deficiência. Disponível em:

<http://www.planalto.gov.br/ccivil_03/_ato2015-2018/2015/lei//13146.htm >. Acesso: 09 de maio de 2017.

BRASIL. Ministério da Educação - MEC - Libras. Disponível em:

<http://portal.mec.gov.br/component/tags/tag/33044>. Acesso: 13 de out. de 2017.

DOMINGOS, Marisa Aparecida. A Escola como Espaço de Inclusão: sentidos e significados produzidos por alunos e professores no cotidiano de uma escola do sistema regular de ensino a partir da inclusão de alunos portadores de necessidades especiais. Dissertação (Mestrado) - Pontifica Universidade Católica de Minas Gerais, Programa de Pós-Graduação em Educação. 2005. Disponível em: <http://www.biblioteca.pucminas.br/teses/Educacao_DomingosMA_1.pdf>. Acesso: 08 de out. de 2017.

FARIA FILHO, Luciano Mendes. Instrução elementar no século XIX. In: LOPES, Eliane Marta Teixeira; FARIA FILHO, Luciano Mendes; VEIGA, Cythia Greive (org.). 500 anos de educação no Brasil. Belo Horizonte: Autêntica, 2010. p. 135-150.

FELIPE, Tanya A. O Discurso verbo-visual na língua brasileira de sinais - Libras. 2013. Bakhtiniana, São Paulo, 8 (2): 67-89, jul./dez. 2013. Disponível em: <http://www.scielo.br/pdf/bak/v8n2/05.pdf>. Acesso: 13 de out. de 2017.

FERNANDES, Sueli. Educação de Surdos. Curitiba: Editora Ibepex, 2 $2^{\underline{a}}$ ed., 2011, $159 \mathrm{p}$.

FERNANDES, Sueli.; MOREIRA, Laura Ceretta. Políticas de educação bilíngue para surdos: o contexto brasileiro. Educar em Revista, Curitiba, Brasil, Edição Especial n. 2/2014, p. 51-69. Editora UFPR. Disponível em: <http://www.scielo.br/pdf/er/nspe2/05.pdf>. Acesso: 25 de março de 2019.

GOLDEFELD, M. A Criança Surda: linguagem e cognição numa perspectiva sociointeracionista. São Paulo: Plexus, 1997.

MACHADO, Luís Eduardo. Gestão estratégica para instituições de ensino superior privadas. FGV Editora, 2008.

MACHADO, Lucília Regina de Souza.; SALLES, Maria de Abreu. Aprendizagem Contextualizada e Educação Superior em Leis Educacionais. Publicado na Revista Educação \& Tecnologia, Belo Horizonte, v. 14, n.1, p. 44-50, 2009. Disponível em:<http://www.mestradoemgsedl.com.br/wpcontent/uploads/2010/06/Aprendizagem -Contextualizada-e-Educa\%C3\%A7\%C3\%A3o-Superior-em-Leis-Educacionais.pdf>. Acesso: 10 de março de 2018. 
MAZZOTTA, Marcos. Educação Especial no Brasil: história e políticas públicas. São Paulo: Cortez, 1996

MORI, Nerli Nonato Ribeiro.; SANDER, Ricardo Ernani. História da Educação dos Surdos no Brasil. Seminário de Pesquisa do PPE. Universidade Estadual de Maringá, 02 a 04 de dezembro de 2015. Disponível em:

<file:///C:/Users/ANGELA\%20COSTA/Downloads/hist\%C3\%B3ria\%20da\%20educa \%C3\%A7\%C3\%A30\%20dos\%20surdos\%20no\%20Brasil\%202015.pdf>. Acesso:09 de dez de 2018.

PERLIN, G. T. Surdos: cultura e pedagogia. In. THOMA, A. S., LOPES, M. C. (org). A invenção da surdez II: espaços e tempos de aprendizagem na educação de surdos. Santa Cruz do Sul, EDUNISC, 2006.

POKER, Rosimar Bortolini. Abordagens de Ensino na Educação da Pessoa com Surdez. Unesp. Libras à Distância. Disponível em:

<https://www.marilia.unesp.br/Home/Extensao/Libras/mec_texto2.pdf>. Acesso: 26 de fev. de 2019.

QUADROS, Ronice Muller de. Inclusão de surdos: uma das peças do quebra-cabeça da educação - volume 11 - D24 - Unesp/UNIVESP - 1a edição 2012. Graduação em Pedagogia. Disponível em: <http://acervodigital.unesp.br/handle/123456789/47938>. Acesso: 13 de out. de 2017.

RAMOS, Denise Marina.; HAYASHI, Maria Cristina Piumbato Innocentini. O lugar da Educação de Surdos nas Dissertações e Teses. Rev. Bras. Ed. Esp., Marília, v.24, n.2, p.247-260, abr.-jun., 2018. Disponível em: <http://dx.doi.org/10.1590/S141365382418000200007>. Acesso: 27 de fev. 2019.

RODRIGUES, Ednalva Gutierrez.; GONTIJO, Cláudia Maria Mendes. Descentralização da Educação. Educ. Pesqui., São Paulo, v.43, n.1, p.229-243, jan./mar.2017. Disponível em: <http://www.scielo.br/pdf/ep/v43n1/1517-9702-ep-431-0229.pdf>. Acesso: 26 de fev. de 2019.

ROSSI, Renata Aparecida. A Libras como disciplina no ensino superior. Revista de Educação. Volume 3, n. 15, 2010. Disponível em:

<http://www.pgsskroton.com.br/seer/index.php/educ/article/viewFile/1867/1772>.

Acesso: 03 de jan. de 2019.

SACKS, O. Vendo Vozes: uma viagem ao mundo dos surdos, Tradução de Laura Teixeira Motta. São Paulo: Companhia das Letras; 1998.

SILVA, D. N. H. Como Brincam as crianças surdas. São Paulo: Plexus Editora, 2002. 
Criar Educação, Criciúma, v. 10, nº1, jan/jul 2021.- PPGE - UNESC - ISSN 2317-2452

SANTANA, Ana Paula.; BERGAMO, Alexandre. Cultura e Identidade Surdas: encruzilhada de Lutas Sociais e Teóricas. Educ. Soc., Campinas, vol. 26, n. 91, p. 565-582, Maio/Ago. 2005. Disponível em: <http://www.cedes.unicamp.br>. Acesso: 19 de fev. de 2018.

SANTOS, Emmanuelle Felix dos. O ensino de libras na formação do professor: um estudo de caso nas licenciaturas da Universidade Estadual de Feira de Santana. Dissertação (Mestrado) - Universidade Estadual de Feira de Santana, Programa de Pós Graduação em Educação. 2015. 210 f. Disponível em:

<http://tede2.uefs.br:8080/handle/tede/280>. Acesso: 05 de março de 2018.

SILVA, J. O. Ações inclusivas no ensino superior brasileiro. Rev. bras. Estud. pedagog. (online), Brasília, v. 95, n. 240, p. 414-430, maio/ago. 2014. Disponível em: <http://www.scielo.br/pdf/rbeped/v95n240/09.pdf>. Acesso: 27 de fev. de 2019.

SILVA NETO, Antenor de Oliveira.; ÁVILA, Éverton Gonçalves.; SALES, Tamara Regina Reis.; AMORIM, Simone Silveira.; NUNES, Andréa Karla.; SANTOS, Vera Maia. Revista Educação Especial. V.31, n. 60, p. 81-92, jan./mar. 2018. Santa Maria. Disponível em: <https://periódicos.ufsm.br/educacaoespecial>. Acesso: 03 de jan. de 2019.

STROBEL, Karin L. Surdos: Vestígios Culturais não Registrados na História. Tese. (Doutorado em Educação) - Faculdade de Educação. UFSC, Florianópolis. 2008. 176 f. Disponível em: <https://repositorio.ufsc.br/handle/123456789/91978>. Acesso em 03 de jan. de 2019. 
Criar Educação, Criciúma, v. 10, no1, jan/jul 2021.- PPGE - UNESC - ISSN 2317-2452

Recebido setembro de 2020

Aprovado abril de 2021 
Criar Educação, Criciúma, v. 10, no1, jan/jul 2021.- PPGE - UNESC - ISSN 2317-2452 